\title{
High expression of SLC26A6 in the kidney may contribute to renal calcification via an SLC26A6-dependent mechanism
}

\author{
Hongyang Jiang ${ }^{1,2}$ ， Gaurab Pokhrel ${ }^{1,2}$, Yinwei Chen ${ }^{1,2}$, Tao Wang ${ }^{1,2}$, Chunping Yin ${ }^{\text {Corresp.. }} 3$, Jihong Liu ${ }^{1,2}$, \\ Shaogang Wang ${ }^{1,2}$, Zhuo Liu Corresp. 1,2 \\ ${ }^{1}$ Department of Urology, Tongji Hospital, Tongji Medical College, Huazhong University of Science and Technology, Wuhan, China \\ 2 Institute of Urology, Tongji Hospital, Tongji Medical College, Huazhong University of Science and Technology, Wuhan, China \\ 3 School of Pharmacy, Tongji Medical College, Huazhong University of Science and Technology, Wuhan, China \\ Corresponding Authors: Chunping Yin, Zhuo Liu \\ Email address: cpyin888@163.com, tjmulz@163.com
}

Background: Solute-linked carrier 26 gene family 6 (SLC26A6), which is mainly expressed in intestines and kidneys, is a multifunctional anion transporter crucial in the transport of oxalate anions. This study aimed to investigate the role of kidney SLC26A6 in urolithiasis.

Methods: Patients were divided into two groups: stone formers and nonstone formers. Samples were collected from patients following nephrectomy. Lentivirus with Slc26a6 (lentivirus-Slc26a6) sequence and lentivirus with siRNA-SIc26a6 (lentivirus-siRNA-SIc26a6) sequence were transfected into rats' kidneys respectively and Slc26a6 expression was detected using Western blot and immunohistochemical analyses. After administering ethylene glycol, oxalate concentration and prevalence of stone formation between the transgenic and control groups were measured using 24-h urine analysis and Von Kossa staining, respectively.

Results: Immunohistochemical and Western blot analyses indicated that stone formers had a significantly higher level of expression of Slc26a6 in the kidney compared with the control group. After lentivirus infection, the urinary oxalate concentration and rate of stone formation in lentivirus-SIc26a6tranfected rats increased remarkably, while lentivirus-siRNA-SIc26a6-transfected rats showed few crystals.

Conclusion: The results showed that high expression levels of renal SLC26A6 may account for kidney stone formation. Downregulating the expression of SLC26A6 in the kidney may be a potential therapeutic target to prevent or treat urolithiasis. 


\section{High expression of SLC26A6 in the kidney may 2 contribute to renal calcification via an SLC26A6- 3 dependent mechanism}

4 Hongyang Jiang 1, 2, Gaurab Pokhrel1, 2, Yinwei Chen 1, 2, Tao Wang1, 2, Chunping Yin ${ }^{3}$,

5 *, Jihong Liu1, 2, Shaogang Wang1, 2, Zhuo Liu1, 2, *

6 'Department of Urology, ${ }^{2}$ Institute of Urology, Tongji Hospital, Tongji Medical College, Huazhong

7 University of Science and Technology, Wuhan 430030, Hubei, China

8 3School of Pharmacy, Tongji Medical College, Huazhong University of Science and Technology, Wuhan

9 430030, Hubei, China

10 *Corresponding author: Zhuo Liu, email: tjmulz@163.com; Chunping Yin, email: cpyin888@163.com

11 Short Title: Renal SLC26A6 promotes calcification 


\section{ABSTRACT}

13 Background: Solute-linked carrier 26 gene family 6 (SLC26A6), which is mainly expressed in intestines 14 and kidneys, is a multifunctional anion transporter crucial in the transport of oxalate anions. This study 15 aimed to investigate the role of kidney SLC26A6 in urolithiasis.

16 Methods: Patients were divided into two groups: stone formers and nonstone formers. Samples were 17 collected from patients following nephrectomy. Lentivirus with SIc26a6 (lentivirus-SIc26a6) sequence 18 and lentivirus with siRNA-SIc26a6 (lentivirus-siRNA-SIc26a6) sequence were transfected into rats' 19 kidneys respectively and Slc26a6 expression was detected using Western blot and 20 immunohistochemical analyses. After administering ethylene glycol, oxalate concentration and 21 prevalence of stone formation between the transgenic and control groups were measured using 24-h 22 urine analysis and Von Kossa staining, respectively.

23 Results: Immunohistochemical and Western blot analyses indicated that stone formers had a 24 significantly higher level of expression of SLC26A6 in the kidney compared with the control group. 25 After lentivirus infection, the urinary oxalate concentration and rate of stone formation in lentivirus26 Slc26a6-tranfected rats increased remarkably, while lentivirus-siRNA-SIc26a6-transfected rats 27 showed few crystals.

28 Conclusion: The results showed that high expression levels of renal SLC26A6 may account for kidney 29 stone formation. Downregulating the expression of SLC26A6 in the kidney may be a potential 30 therapeutic target to prevent or treat urolithiasis. 


\section{INTRODUCTION}

33 Nephrolithiasis is one of the most common urological conditions. An increasing prevalence and

34 incidence of the disease have been observed over the last several decades (Wang et al., 2017).

35 Recurrence is a significant cause of the morbidity of the disease, causing a significant burden on

36 the health care system(Khan, 2018). Calcium oxalate is the most prevalent type of kidney stone.

37 A major risk factor for kidney stone formation is hyperoxaluria, which leads to an increase in

38 urinary saturation of calcium oxalate and formation of calcium oxalate stones (Robertson \&

39 Peacock, 1980; Noori et al., 2014). Hyperoxaluria is caused mainly by the oxalate metabolism

40 defect in the intestines and kidneys(Agrawal, 2017).

41 The Solute-linked carrier 26 (Slc26) gene family encodes anion exchangers capable of transporting 42 different monovalent and divalent anions, including oxalate, $\mathrm{Cl}^{-}, \mathrm{HCO}_{3}^{-}$, and sulfate(Aronson \& 43 Giebisch, 1997; Ko et al., 2002; Ohana et al., 2013). Oxalate is the end product of metabolism that must be excreted or sequestered(Marengo \& Romani, 2008). SLC26A6, A1, and A7 are the three major anion transporters that mediate oxalate excretion and absorption causing stone formation(Burckhardt \& Burckhardt, 2003; Hatch \& Freel, 2005; Voss et al., 2006). SLC26A6 is a multiple anion transporter expressed mainly in the apical membrane of the intestines and kidneys. SLC26A6 has remarkable tissue-specific properties. It mediates the exchange of a cluster of anions including $\mathrm{Cl}^{-}, \mathrm{HCO}_{3}{ }^{-}$, sulfate, and oxalate, and is associated with oxalate transportation(Chernova et al., 2005; Clark et al., 2008). In the intestine, oxalate homeostasis is regulated mainly by SLC26A6-mediated oxalate secretion, imbalance of which results in hyperoxaluria and hyperoxalemia(Freel et al., 2006; Aronson, 2010). Knauf et al. demonstrated that intestinal oxalate secretion depends on an SLC26A6-dependent transcellular mechanism, while the absorption of oxalate takes place via a paracellular channel(Mount \& Romero, 2004; Knauf et al., 2011). Thus, enhancement in enteric oxalate secretion remains a therapeutic target, especially because duodenal oxalate absorption is entirely paracellular. However, $90 \%-95 \%$ endogenous oxalate is excreted by 
58 al., 1981; Boer et al., 1985; Brzica et al., 2013). SLC26A6 not only mediates the secretion of

59 oxalate in the intestine but also powers the gradient for transmembrane movement, including

60 secretion and absorption in the kidney (Knauf et al., 2011; Alper \& Sharma, 2013). This study

61 hypothesized that the expression of SLC26A6 in the kidney would account for the prevalence of

62 stones by affecting oxalate secretion.

\section{MATERIALS AND METHODS}

\section{Patients}

\section{Ethical statement}

66 This study was performed at the Tongji Hospital, and the ethical approval was given by the

67 Medical Ethics Committee at Tongji Hospital, Tongji Medical College, Huazhong University of 68 Science and Technology (Wuhan, China; TJ-C20141225). All patients signed the informed 69 consent form to participate. All methods were performed in full compliance with the Declaration 70 of Helsinki.

71 Patients

72 Ten patients with calcium oxalate stones (stone group) and 10 patients with nonstone diseases, 73 including tumor or tuberculosis (control group), between November 2015 and October 2016 in 74 Tongji Hospital were included in this study. The patients in the stone group had undergone 75 nephrectomy for severe hydronephrosis leading to the loss of renal function (Assimos et al., 2016). 76 Clinical and laboratory characteristics of the patients are summarized in Table 1. The patients of 77 calcium oxalate stones were selected according to previous records of hyperoxaluria and by the 78 analysis of stones previously eliminated.

Analysis of stone components 
80 About $1.5 \mathrm{mg}$ of stones were taken out and ground into powder. It was then mixed with $250 \mathrm{mg}$

81 potassium bromide. This mixture was dried and subjected to a pressure of $20 \mathrm{MPa}$ to make tablets

82 with a thickness of $0.3-0.5 \mathrm{~mm}$. Then, the spectral characteristic peaks of tablets were measured 83 using an LIIR20 infrared spectrum analyzer (Lambda, Tianjin, China). The components were 84 evaluated by comparing with the standard image.

\section{Analysis of 24-h urine components of the stone and control groups}

86 The standard protocol was followed to collect 24-h urine collected from the patients. After

87 measuring the $\mathrm{pH}$ of each sample, $500 \mu \mathrm{L}$ of $6 \mathrm{~mol} / \mathrm{L}$ hydrochloric acid was added into each 10

$88 \mathrm{~mL}$ fresh urine sample (Wu et al., 2015). Ions levels were measured by ion chromatography (883

89 Basic IC plus; Metrohm AG, Herisau, Switzerland) according to the methods described in a 90 previous study(Wu et al., 2015). After high speed centrifugation by pretreatment column and $910.25 \mu \mathrm{m}$ filter, samples were to be added into chromatographic column and analyzed the ion 92 electrical conductance of samples(Chen et al., 2013).

\section{Collection of kidney tissue samples}

94 Renal cortex tissue was obtained using sterilized scissors following nephrectomy. Kidney tissue

95 far away from a primary lesion was chosen in patients with tuberculosis and tumors who underwent 96 nephrectomy and served as the control group. The tissues were stored at $-80^{\circ} \mathrm{C}$ and fixed with $4 \%$ 97 paraformaldehyde (Boster, China) at room temperature for further analysis.

98 Western blot and immunohistochemical (IHC) assays to detect the expression of

99 SLC26A6 in the kidney

100 Samples were dissociated using radio immunoprecipitation assay (RIPA) and

101 phenylmethanesulfonyl fluoride. The protein $(40 \mu \mathrm{g} / \mathrm{lane})$ was electrophoresed on $10 \%$ sodium 102 dodecyl sulfate-polyacrylamide gels (SDS-page) and transferred onto polyvinylidene fluoride 
103 membranes (Immobilon-P Transfer Membrane; Millipore Corporation, MA, USA). The protein

104 samples were equally mixed, and the expression of SLC26A6 in the two groups was analyzed. The 105 primary antibody was goat anti-SLC26A6 (1:200; Santa Cruz, CA, USA) or mouse $\beta$-actin (1:500;

106 Boster). The secondary antibody was rabbit anti-goat (1:5000; Boster) or goat anti-mouse (1:5000;

107 Boster). After incubation with the secondary antibody at room temperature for $2 \mathrm{~h}$, proteins were 108 detected with the Bio-Rad Clarity Western Enhanced Chemiluminescence (ECL) Substrate (Bio-

109 Rad Laboratories, CA, USA) and ECL detection system (GeneGnome, MD, USA). The IHC

110 assays were performed according to the standard protocol, and the dilution rate of anti-SLC26A6

111 primary antibody was 1:100. Microscopy (BX53, Olympus, Japan) was used to observe the

112 expression of SLC26A6. Fluorescence intensities were measured using ImageJ software (National

113 Institutes of Health, Bethesda, MD, USA).

\section{Animal study}

\section{Ethical statement}

116 The experimental protocol was conducted in accordance with the institutional ethical committee

117 of Tongji Hospital, Tongji Medical College, Huazhong University of Science and Technology

118 according to the "Guidelines for Experimental Animal Ethical Committee of Huazhong University

119 of Science and Technology". This study was approved by the Ethical Committee (TJ-A 20141219).

120 Animal model

121 A total of 40 male Sprague-Dawley rats (275-300 g) were obtained from the Animal Center of

122 Tongji Medical College, Huazhong University of Science and Technology. They were

123 reacclimatized to $12-\mathrm{h}$ light/dark cycles at $23^{\circ} \mathrm{C}$ for 1 week prior to the start of experiments in a

124 specific pathogen-free animal house with a relative humidity of $45 \%-55 \%$. They were maintained

125 on a diet consisting of standard laboratory chow and had free access to food. They were randomly

126 divided into 4 groups (10 rats in each group): negative control, lentivirus (lv-SLC26A6), siRNA-

127 lentivirus (siRNA-SLC26A6), and vector groups. 
129 The Slc26a6 sequence (National Center for Biotechnology Information, NCBI Gene ID: 301010)

130 was selected according to the NCBI GeneBank. To knockdown rat SLC26A6, lentiviral vector

131 piLenti-siRNA-RFP-based shRNA against Slc26a6 were constructed. The targeting sequence for

132 shSlc26a6 is 5'-GGGAACTACTCAAGCTAAT-3'. The sequences were synthesized and inserted

133 into the vector pWSLV as pWSLV-05-Slc26a6 and pilentivirus as piLenti-siRNA (Slc26a6)-RFP.

134 Recombinant lentiviruses were packaged in HEK293T cells by co-transfection of Slc26a6-

135 encoding plasmids and helper plasmids, such as pRSV-REV, pMDLg and pVSV-G, with

136 lipofectamine 2000 in proportion with $1: 2: 1: 1$, and the titer of lentivirus was calculated by

137 gradually dilute the concentrated raw virus until observe just one fluorescence in cells. Then,

138 HEK293T cells were seeded in $10-\mathrm{cm}$ dishes until they reached a confluence of $80 \%-90 \%$. The

139 infection complex was directly added to each dish. The cells were then incubated in a $5 \% \mathrm{CO}_{2}$

140 incubator at $37^{\circ} \mathrm{C}$ overnight. Lentivirus particle-containing culture medium was harvested $48 \mathrm{~h}$

141 post infection. The final titers of the lentiviral vector contained $10^{9} \mathrm{Tu} / \mathrm{mL}$.

142 Lentivirus infection into the kidneys of rats

143 The rats were placed in a prone position and anesthetized with sodium pentobarbital (40 mg/kg).

$1442 \times 10^{7} \mathrm{Tu}$ per rat lentivirus were applied to subcapsular renal injection (2-3 points per kidney).

145 Lentivirus subcapsular renal infection was successfully accomplished according to the previously

146 published protocol(Zmuda, Powell \& Hai, 2011). Every effort was made to minimize suffering.

147 Identification of infection using frozen sections and expression of SIc26a6 in transgenic

148 rats

149 Two weeks after the successful infection of lentivirus into the kidneys of rats, the kidneys and

150 duodenal segments of four rats from different groups $(n=4 /$ group $)$ were harvested under

151 anesthesia. The tissues were instantly frozen in liquid nitrogen and stored at $-80^{\circ} \mathrm{C}$. After 
152 embedding and routine processing, serial sections were observed under a fluorescent microscope

153 to identify the fluorescent protein. Then IHC and Western blot assays were performed as described

154 in the "Patients" section to measure the expression of Slc26a6 protein.

155 Crystal deposition and urinary oxalate in the kidneys of rats

156 Ethylene glycol was dissolved in water to titrate $1 \%$ ethylene glycol. The remaining animals $(\mathrm{n}=$

157 6/group) had free access to $1 \%$ ethylene glycol. After 2 weeks of $1 \%$ ethylene glycol treatment in

158 all four groups, urine specimens from each group were collected at 24-h intervals using a

159 metabolism cage. Ion chromatography (883 Basic IC plus; Metrohm AG, Herisau, Switzerland)

160 was used to detect 24-h urinary oxalate according to the methods described in a previous

161 study(Chen et al., 2013). The rats were killed under anesthesia, and kidneys were removed. Von

162 Kossa staining was used to identify crystal formation in kidneys.

\section{Statistical analysis}

164 Data were presented as mean \pm standard deviation. The statistical analysis was performed using 165 two-way analysis of variance. Differences were considered significant if the $\mathrm{P}$ value was $<0.05$.

166 All analyses were performed using SPSS version 22.0 (Statistical Software for Social Sciences, 167 Inc., IL, USA).

168 Results

169 Patient characteristics and urine biochemistry

170 From 2015 to 2016, a total of 20 subjects (10 stone formers and 10 nonstone formers) were

171 recruited in this study (Table 1). The average age in both groups was $56.4 \pm 5.32$ vs $54.8 \pm 14.76$

172 years (stone formers vs nonstone formers). Stone formers included patients with kidney and upper

173 ureteral stones, while the nonstone formers included patients suffering from renal tuberculosis or

174 tumors. Stones were collected after nephrectomy, and subsequent component analysis of the stone 
175 was performed using a stone composition analyzer; $\mathrm{CaC}_{2} \mathrm{O}_{4}$ and carbonated apatite were detected

176 as the main components.

177 After recruiting idiopathic stone formers, 24-h urine was collected and the urinary oxalate,

178 calcium, citrate, magnesium, phosphorus, and $\mathrm{pH}$ were measured (Fig. 1A). The stone formers had

179 high levels of urinary oxalate $(65.72 \pm 12.44$ vs $31.63 \pm 7.91 \mathrm{mg} / 24 \mathrm{~h}, \mathrm{P}<0.05)$, and calcium

$180 \quad(382.61 \pm 104.06$ vs $226.89 \pm 66.01 \mathrm{mg} / 24 \mathrm{~h}, \mathrm{P}<0.05)$, and low levels of urinary citrate $(344.93$

$181 \pm 57.78$ vs $444.91 \pm 65.26 \mathrm{mg} / 24 \mathrm{~h}, \mathrm{P}<0.05)$ compared with the control group. However, no

182 significant difference in urinary magnesium $(84.23 \pm 9.91 \mathrm{vs} 90.17 \pm 9.35 \mathrm{mg} / 24 \mathrm{~h}, \mathrm{P}=0.18)$ and

183 phosphorus $(1006.85 \pm 466.87$ vs $735.11 \pm 164.87 \mathrm{mg} / 24 \mathrm{~h}, \mathrm{P}=0.10)$ was noted between the two

184 groups. Urinary $\mathrm{pH}(6.25 \pm 0.49$ vs $6.30 \pm 0.35, \mathrm{P}=0.79)$ showed no remarkable difference

185 between the two groups.

186 Expression of SLC26A6 in patients with calcium oxalate stones

187 After successful nephrectomy, IHC and Western blot analyses were performed to detect the 188 expression of SLC26A6 in the renal tissue (Fig.S1 and Fig.S2). Both IHC and Western blot assays 189 showed significantly higher expression of renal SLC26A6 in the stone formers than in the control 190 group (Fig. 1B to 1E).

191 Lentivirus preparation and infection detection

192 Lentiviruses (Fig. 2A), namely pWSLV-05-Slc26a6 (lv-Slc26a6) and piLenti-siRNA (Slc26a6)193 red fluorescent protein (RFP) (siRNA-Slc26a6), were marked with RFP and anti-puromycin gene.

194 After subcapsular injection into the kidneys of rats for 2 weeks, the kidney and duodenal frozen 195 sections were examined under a fluorescence microscope. Lentivirus infection was observed to be 196 successful in the kidney of transfected groups compared with the control group (Fig. 2B).

197 Comparison of the expression of Slc26a6 in the kidneys and duodenum of rats 
198 Western blot and IHC analyses were used after successful 1v-Slc26a6 and siRNA-Slc26a6

199 infection to demonstrate the variation in the expression of Slc26a6 in the kidneys and duodenum

200 of rats (Fig. 3A to 3D). No significant difference was observed in the expression of Slc26a6 among

201 the Slc26a6-lentivirus, siRNA-Slc26a6, vector-lentivirus, and normal control groups in duodenal

202 tissue, suggesting that lentivirus did not alter the expression of duodenal Slc26a6. Western blot

203 and IHC analyses of renal tissue of lv-Slc26a6-transfected rats showed higher expression of

204 Slc26a6 compared with that in the normal control groups. Transfecting siRNA-Slc26a6 decreased

205 the expression of Slc26a6 in the kidneys, whereas transfecting vector-lentivirus did not show any

206 significant change in the expression of Slc26a6.

207 Rate of stone formation and urinary oxalate concentration in rats

208 The rate of stone formation and urinary oxalate concentration in rats with 1v-Slc26a6 (Slc26a6 209 group) increased remarkably, whereas the rate in those with siRNA-Slc26a6 (siRNA group)

210 decreased after lentivirus infection. The supplementation of drinking water with $1.0 \%$ ethylene

211 glycol (EG) induced hyperoxaluria, and the subsequent oxalate excretion was measured. The

212 urinary oxalate concentration of rats was $71.90 \pm 17.21 \mu \mathrm{mol} / 24 \mathrm{~h}, 32.80 \pm 12.20 \mu \mathrm{mol} / 24 \mathrm{~h}, 47.73$

$213 \pm 10.50 \mu \mathrm{mol} / 24 \mathrm{~h}$, and $53.24 \pm 14.97 \mu \mathrm{mol} / 24 \mathrm{~h}$, in the lv-Slc26a6, siRNA-Slc26a6, control, and

214 vector groups, respectively (Fig. 4A). Von Kossa staining was used to quantify the mineralization

215 status. The result showed $11.77 \pm 3.56 /$ field, $5.83 \pm 3.47 /$ field, $9.00 \pm 2.11 /$ field, and $8.78 \pm$

216 3.34/field in the Slc26a6, siRNA, control, and vector groups, respectively (Fig. 4B and 4C).

\section{Discussion}

218 Oxalate secretion in proximal tubules is associated with the expression of both basolateral

219 SLC26A1 and apical SLC26A6 in the kidneys(Xie et al., 2002; Freel et al., 2006). Numerous

220 studies have demonstrated a close relationship between the expression of SLC26A6 and kidney

221 stone formation, but its exact role in the disease remains unknown(Hirata et al., 2012; Ohana et

222 al., 2013; Landry et al., 2016; Lu et al., 2016). Jiang et al. demonstrated that Slc26a6 ${ }^{-/}$mice had a 
223 susceptibility to urolithiasis(Jiang et al., 2006). The present case-control study examined the

224 relationship between kidney stones and the role of SLC26A6 in stone formation.

225 Tissue samples were collected from patients with renal stones (stone former group) and patients

226 suffering from renal tuberculosis or tumors (control group) to reveal the role of renal SLC26A6 in

227 stone formers. Western blot and IHC analysis results showed a direct relationship between kidney

228 stone formation and expression of SLC26A6. However, whether the increased expression of

229 SLC26A6 in the stone group is the cause or result of the disease was difficult to predict.

230 Furthermore, infection of lentivirus with Slc26a6 sequence and lentivirus with siRNA anti-Slc26a6

231 into the kidneys of rats was achieved. The renal subcapsular injection technique was used to ensure

232 the organ-specific expression of the virus and avoid expression in other organs especially in the

233 intestinal tract(Zmuda, Powell \& Hai, 2011). Figure 2B shows the successful infection of the virus

234 and change in the expression of Slc26a6 specifically in the kidneys. An increase in oxalate

235 excretion and crystal formation was noted with an increase in the expression of Slc26a6, and vice

236 versa. A classical research demonstrated that intestinal oxalate secretion defect in Slc26a6-null

237 mice could result in enhanced net absorption of oxalate leading to a high incidence of calcium

238 oxalate urolithiasis(Jiang et al., 2006). Different from the whole-body knockout, only the

239 expression of renal Slc26a6 was regulated in the present study. Therefore, intestinal Slc26a6 that

240 mediates oxalate excretion could function properly and not result in enhanced net absorption of

241 oxalate. Besides, only a partial but significant defect in sulfate-oxalate exchange was observed

242 compared with the complete loss of $\mathrm{Cl}^{-}$-oxalate exchange activity in Slc26a6-null mice(Jiang et

243 al., 2006). This finding was consistent with the result of the present study that the concentration of

244 oxalate was higher in rats with lv-Slc26a6 than in normal rats. Therefore, upregulated and

245 downregulated renal Slc26a6 could lead to enhanced and reduced net excretion of oxalate that

246 manifested as higher and lower urinary oxalate concentration, respectively (Fig. 5 shows the

247 proposed mechanisms of oxalate transport across the renal epithelium in the proximal 
248 tubule)(Kleta, 2006). Moreover, the expression of Slc26a6 on renal tubular epithelial cells

249 mediated influx or outflow of oxalate, leading to an increase in the intracellular oxalate content.

250 Oxalate in the cell could stimulate the production of reactive oxygen species and inflammatory

251 factors, resulting in cellular damage(Patel et al., 2006; Zhang et al., 2017). Injury in renal tubular

252 epithelial cells (NRKs) is an initial mechanism for crystal nucleation, attachment, and retention,

253 which was consistent with the result of the present study(Jonassen et al., 2003; Khan, 2004; Zuo

254 et al., 2011; Abhishek et al., 2017).

255 The animal experiment results showed that Slc26a6 was one of the causes of kidney stone 256 formation. The potential mechanism might be that Slc26a6 led to the secretion and reabsorption 257 of oxalate, resulting in higher oxalate concentration in urine and interstitium(Marengo \& Romani, 258 2008). A high-oxalate concentration could lead to tissue inflammation and crystal deposition in a 259 short time(Albert et al., 2017). Therefore, the lv-Slc26a6 group had the highest level of crystals 260 and the siRNA-Slc26a6 group had the least level of crystals (Fig. 4C). Besides, only one time point 261 (2 weeks) for the crystal production was observed in this study. The crystals in the kidney might 262 be slowly eliminated with time. Therefore, studies on setting up a time gradient are needed in the 263 future(Okada et al., 2010; Yasui et al., 2014).

264 This study showed that the increased expression of renal Slc26a6 caused higher oxalate 265 concentration in urine, leading to an increased crystal deposition. Moreover, reducing the 266 expression of renal Slc26a6 by siRNA injection attenuated stone formation. However, the study 267 had several limitations. First, due to the small cohort size, future studies with a larger number of 268 patients are needed to confirm the results. Second, Slc26a6 was an important but not the only 269 oxalate transporter; therefore, measuring oxalate flux mediated by other proteins and oxalate 270 concentration in other areas help better understanding of oxalate transport. Third, all experimental 271 procedures were subject to ethical approval. Patients with renal tuberculosis and cancer were 272 selected as the control group because it was nearly impossible to acquire a sample of normal human 
273 renal tissue for this study. Moreover, the results of previous studies including samples from

274 patients with cancer as the control group have been widely accepted(Chi et al., 2017). Hence,

275 further studies with a large sample size are needed to address other similar mechanisms involved

276 in calcium oxalate stone formation and validate the role of SLC26A6 in oxalate stone formation.

\section{Conclusions}

278 In conclusion, the present study demonstrated that the overexpression of Slc26a6 in the kidneys

279 increased oxalate excretion and urinary oxalate concentration, contributing to an increase in the

280 prevalence of stone formation. Downregulating the expression of SLC26A6 in the kidneys might

281 be a potential therapeutic target to prevent or treat urolithiasis.

282

283

References

284

285

286

287

288

289

290

291

292

293

294

295

296

297

298

299

300

301

Abhishek A, Benita S, Kumari M, Ganesan D, Paul E, Sasikumar P, Mahesh A, Yuvaraj S, Ramprasath T, Selvam GS 2017. Molecular analysis of oxalate-induced endoplasmic reticulum stress mediated apoptosis in the pathogenesis of kidney stone disease. Journal of physiology and biochemistry 73:561-573. DOI: 10.1007/s13105-017-0587-8.

Agrawal V 2017. Enteric Hyperoxaluria, Calcium Oxalate Nephrolithiasis, and Oxalate Nephropathy After Roux-en-Y Gastric Bypass. In: Metabolism and Pathophysiology of Bariatric Surgery. Elsevier, 361-370. DOI: 10.1016/B978-0-12-804011-9.00044-3. Albert A, Tiwari V, Paul E, Ponnusamy S, Ganesan D, Prabhakaran R, Mariaraj Sivakumar S, Govindan Sadasivam S 2017. Oral administration of oxalate enriched spinach extract as an improved methodology for the induction of dietary hyperoxaluric nephrocalcinosis in experimental rats. Toxicology mechanisms and methods:1-28. DOI:

10.1080/15376516.2017.1388459.

Alper SL, Sharma AK 2013. The SLC26 gene family of anion transporters and channels. Molecular aspects of medicine 34:494-515. DOI: 10.1016/j.mam.2012.07.009.

Aronson PS 2010. Role of SLC26A6-mediated $\mathrm{Cl}^{-}$-oxalate exchange in renal physiology and pathophysiology. Journal of nephrology 23 Suppl 16:S158-64.

Aronson PS, Giebisch G 1997. Mechanisms of chloride transport in the proximal tubule. American Journal of Physiology - Renal Physiology 273. 
302

303

304

305

306

307

308

309

310

311

312

313

314

315

316

317

318

319

320

321

322

323

324

325

326

327

328

329

330

331

332

333

334

335

336

337

338

339

340

Assimos D, Krambeck A, Miller NL, Monga M, Murad MH, Nelson CP, Pace KT, Pais VM, Pearle MS, Preminger GM, Razvi H, Shah O, Matlaga BR 2016. Surgical Management of Stones: American Urological Association/Endourological Society Guideline, PART I. The Journal of urology 196:1153-1160. DOI: 10.1016/j.juro.2016.05.090.

Boer P, Prenen JA, Koomans HA, Dorhout Mees EJ 1985. Fractional oxalate clearance in subjects with normal and impaired renal function. Nephron 41:78-81.

Brzica H, Breljak D, Burckhardt BC, Burckhardt G, Sabolić I 2013. Oxalate: from the environment to kidney stones. Arhiv za higijenu rada i toksikologiju 64:609-630. DOI: 10.2478/10004-1254-64-2013-2428.

Burckhardt BC, Burckhardt G 2003. Transport of organic anions across the basolateral membrane of proximal tubule cells. Reviews of physiology, biochemistry and pharmacology 146:95-158. DOI: 10.1007/s10254-002-0003-8.

Chen X, Gu X, Sun X, Zhang L, Xu Y 2013. The study of the determination of oxalate and citrate in human urine by lon chromatography method. J Clin Urology (China) 28:437-439. DOI: $10.13201 /$ j.issn.1001-1420.2013.06.014.

Chernova MN, Jiang L, Friedman DJ, Darman RB, Lohi H, Kere J, Vandorpe DH, Alper SL 2005. Functional comparison of mouse slc26a6 anion exchanger with human SLC26A6 polypeptide variants: differences in anion selectivity, regulation, and electrogenicity. The Journal of biological chemistry 280:8564-8580. DOI: 10.1074/jbc.M411703200.

Chi H-H, Hua K-F, Lin Y-C, Chu C-L, Hsieh C-Y, Hsu Y-J, Ka S-M, Tsai Y-L, Liu F-C, Chen A 2017. IL-36 Signaling Facilitates Activation of the NLRP3 Inflammasome and IL-23/IL17 Axis in Renal Inflammation and Fibrosis. Journal of the American Society of Nephrology 28:2022-2037. DOI: 10.1681/ASN.2016080840.

Clark JS, Vandorpe DH, Chernova MN, Heneghan JF, Stewart AK, Alper SL 2008. Species differences in Cl- affinity and in electrogenicity of SLC26A6-mediated oxalate/Cl- exchange correlate with the distinct human and mouse susceptibilities to nephrolithiasis. The Journal of physiology 586:1291-1306. DOI: 10.1113/jphysiol.2007.143222.

Freel RW, Hatch M, Green M, Soleimani M 2006. Ileal oxalate absorption and urinary oxalate excretion are enhanced in Slc26a6 null mice. American journal of physiology. Gastrointestinal and liver physiology 290:G719-28. DOI: 10.1152/ajpgi.00481.2005.

Hatch M, Freel RW 2005. Intestinal transport of an obdurate anion: oxalate. Urological Research 33:1-16. DOI: 10.1007/s00240-004-0445-3.

Hirata T, Cabrero P, Berkholz DS, Bondeson DP, Ritman EL, Thompson JR, Dow JAT, Romero MF 2012. In vivo Drosophilia genetic model for calcium oxalate nephrolithiasis. American Journal of Physiology - Renal Physiology 303:F1555-62. DOI:

10.1152/ajprenal.00074.2012.

Jiang Z, Asplin JR, Evan AP, Rajendran VM, Velazquez H, Nottoli TP, Binder HJ, Aronson PS 2006. Calcium oxalate urolithiasis in mice lacking anion transporter Slc26a6. Nature genetics 38:474-478. DOI: 10.1038/ng1762. 
341 Jonassen JA, Cao LC, Honeyman T, Scheid CR 2003. Mechanisms mediating oxalate-induced

342

343

344

345

346

347

348

349

350

351

352

353

354

355

356

357

358

359

360

361

362

363

364

365

366

367

368

369

370

371

372

373

374

375

376

377

378

379 alterations in renal cell functions. Critical Reviews in Eukaryotic Gene Expression 13:55-72. DOI: 10.1615/CritRevEukaryotGeneExpr.v13.i1.50.

Khan A 2018. Prevalence, pathophysiological mechanisms and factors affecting urolithiasis. International urology and nephrology 25:49-8. DOI: 10.1007/s11255-018-1849-2.

Khan SR 2004. Role of renal epithelial cells in the initiation of calcium oxalate stones. Nephron Experimental Nephrology 98:e55-60. DOI: 10.1159/000080257.

Kleta R 2006. A key stone cop regulates oxalate homeostasis. Nature genetics 38:403-404. DOI: 10.1038/ng0406-403.

Knauf F, Ko N, Jiang Z, Robertson WG, Van Itallie CM, Anderson JM, Aronson PS 2011. Net intestinal transport of oxalate reflects passive absorption and SLC26A6-mediated secretion. Journal of the American Society of Nephrology : JASN 22:2247-2255. DOI: 10.1681/ASN.2011040433.

Ko SBH, Shcheynikov N, Choi JY, Luo X, Ishibashi K, Thomas PJ, Kim JY, Kim KH, Lee MG, Naruse S, Muallem S 2002. A molecular mechanism for aberrant CFTR-dependent $\mathrm{HCO}(3)(-)$ transport in cystic fibrosis. The EMBO journal 21:5662-5672. DOI: 10.1093/emboj/cdf580.

Landry GM, Hirata T, Anderson JB, Cabrero P, Gallo CJR, Dow JAT, Romero MF 2016. Sulfate and thiosulfate inhibit oxalate transport via a dPrestin (Slc26a6)-dependent mechanism in an insect model of calcium oxalate nephrolithiasis. American Journal of Physiology - Renal Physiology 310:F152-9. DOI: 10.1152/ajprenal.00406.2015.

Lu X, Sun D, Xu B, Pan J, Wei Y, Mao X, Yu D, Liu H, Gao B 2016. In Silico Screening and Molecular Dynamic Study of Nonsynonymous Single Nucleotide Polymorphisms Associated with Kidney Stones in the SLC26A6 Gene. The Journal of urology 196:118-123. DOI: 10.1016/j.juro.2016.01.093.

Marengo SR, Romani AMP 2008. Oxalate in renal stone disease: the terminal metabolite that just won't go away. Nature clinical practice. Nephrology 4:368-377. DOI: 10.1038/ncpneph0845.

Mount DB, Romero MF 2004. The SLC26 gene family of multifunctional anion exchangers. Pflügers Archiv - European Journal of Physiology 447:710-721. DOI: 10.1007/s00424-0031090-3.

Noori N, Honarkar E, Goldfarb DS, Kalantar-Zadeh K, Taheri M, Shakhssalim N, Parvin M, Basiri A 2014. Urinary lithogenic risk profile in recurrent stone formers with hyperoxaluria: a randomized controlled trial comparing DASH (Dietary Approaches to Stop Hypertension)style and low-oxalate diets. American journal of kidney diseases : the official journal of the National Kidney Foundation 63:456-463. DOI: 10.1053/j.ajkd.2013.11.022.

Ohana E, Shcheynikov N, Moe OW, Muallem S 2013. SLC26A6 and NaDC-1 transporters interact to regulate oxalate and citrate homeostasis. Journal of the American Society of Nephrology 24:1617-1626. DOI: 10.1681/ASN.2013010080. 
380 Okada A, Yasui T, Fujii Y, Niimi K, Hamamoto S, Hirose M, Kojima Y, Itoh Y, Tozawa K,

381

382

383

384

385

386

387

388

389

390

391

392

393

394

395

396

397

398

399

400

401

402

403

404

405

406

407

408

409

410

411

412

413

414

415

416

417 Hayashi Y, Kohri K 2010. Renal macrophage migration and crystal phagocytosis via inflammatory-related gene expression during kidney stone formation and elimination in mice: Detection by association analysis of stone-related gene expression and microstructural observation. Journal of bone and mineral research : the official journal of the American Society for Bone and Mineral Research 25:2701-2711. DOI: 10.1002/jbmr.158.

Patel AB, Robertson WG, Choong S, Hothersall JS 2006. Heat-shock protein 25 ameliorates calcium oxalate crystal-mediated oxidative stress in renal epithelial cells. BJU International 98:1094-1099. DOI: 10.1111/j.1464-410X.2006.06478.x.

Prenen JA, Boer P, Dorhout Mees EJ, Endeman HJ, Yoe OH 1981. Determination of oxalic acid clearance and plasma concentration by radioisotope infusion. Results in a family with hyperoxaluria. Acta medica Scandinavica 209:87-91.

Robertson WG, Peacock M 1980. The cause of idiopathic calcium stone disease: hypercalciuria or hyperoxaluria? Nephron 26:105-110.

Voss S, Hesse A, Zimmermann DJ, Sauerbruch T, Unruh von GE 2006. Intestinal oxalate absorption is higher in idiopathic calcium oxalate stone formers than in healthy controls: measurements with the [(13)C2] oxalate absorption test. JURO 175:1711-1715. DOI: 10.1016/S0022-5347(05)01001-3.

Wang W, Fan J, Huang G, Li J, Zhu X, Tian Y, Su L 2017. Prevalence of kidney stones in mainland China: A systematic review. Nature Publishing Group 7:41630. DOI: $10.1038 /$ srep41630.

Wu W, Yang D, Tiselius H-G, Ou L, Mai Z, Chen K, Zhu H, Xu S, Zhao Z, Zeng G 2015. Collection and storage of urine specimens for measurement of urolithiasis risk factors. Urology 85:299-303. DOI: 10.1016/j.urology.2014.10.030.

Xie Q, Welch R, Mercado A, Romero MF, Mount DB 2002. Molecular characterization of the murine Slc26a6 anion exchanger: functional comparison with Slc26a1. American Journal of Physiology - Renal Physiology 283:F826-38. DOI: 10.1152/ajprenal.00079.2002.

Yasui T, Kobayashi T, Okada A, Hamamoto S, Hirose M, Mizuno K, Kubota Y, Umemoto Y, Kawai N, Tozawa K, Gao B, Kohri K 2014. Long-term follow-up of nephrotoxicity in rats administered both melamine and cyanuric acid. BMC research notes 7:87. DOI: 10.1186/1756-0500-7-87.

Zhang J, Wang Q, Xu C, Lu Y, Hu H, Qin B, Wang Y, He D, Li C, Yu X, Wang S, Liu J 2017. MitoTEMPO Prevents Oxalate Induced Injury in NRK-52E Cells via Inhibiting Mitochondrial Dysfunction and Modulating Oxidative Stress. Oxidative Medicine and Cellular Longevity 2017:7528090-9. DOI: 10.1155/2017/7528090.

Zmuda EJ, Powell CA, Hai T 2011. A Method for Murine Islet Isolation and Subcapsular Kidney Transplantation. JoVE (Journal of Visualized Experiments):e2096-e2096. DOI: $10.3791 / 2096$. 
418 Zuo J, Khan A, Glenton PA, Khan SR 2011. Effect of NADPH oxidase inhibition on the 419 expression of kidney injury molecule and calcium oxalate crystal deposition in hydroxy-L420 proline-induced hyperoxaluria in the male Sprague-Dawley rats. Nephrology Dialysis 421 Transplantation 26:1785-1796. DOI: 10.1093/ndt/gfr035.

422 


\section{Figure 1}

24-h urine analysis and the expression of SLC26A6 in the kidneys of stone formers and nonstone formers.

(A) 24-h urinary analysis of stone formers and nonstone formers. $n=10$. Compared with the nonstone formers, stone formers had a higher level of urinary oxalate, calcium and a lower urinary citrate. No significant difference was observed in urinary phosphorus, magnesium and $\mathrm{pH}$ between the two groups. (B, C) Western blot analysis of expression of SLC26A6 from kidney of stone formers and nonstone formers. Densitometry values were normalized to respective $\beta$-actin values before statistical analysis. $n=10$. (D, E) One representative image for each group. A similar trend was seen in the IHC analysis (upper magnification: '200, lower magnification: $\times 800$ ). The asterisk $(*)$ denotes glomerulus, and the arrow points to SLC26A6 protein. The mean percentage of SLC26A6 is shown in the column diagram. $n=10$. The data are expressed as means \pm standard deviation (SD); $* P<0.05$. 
A
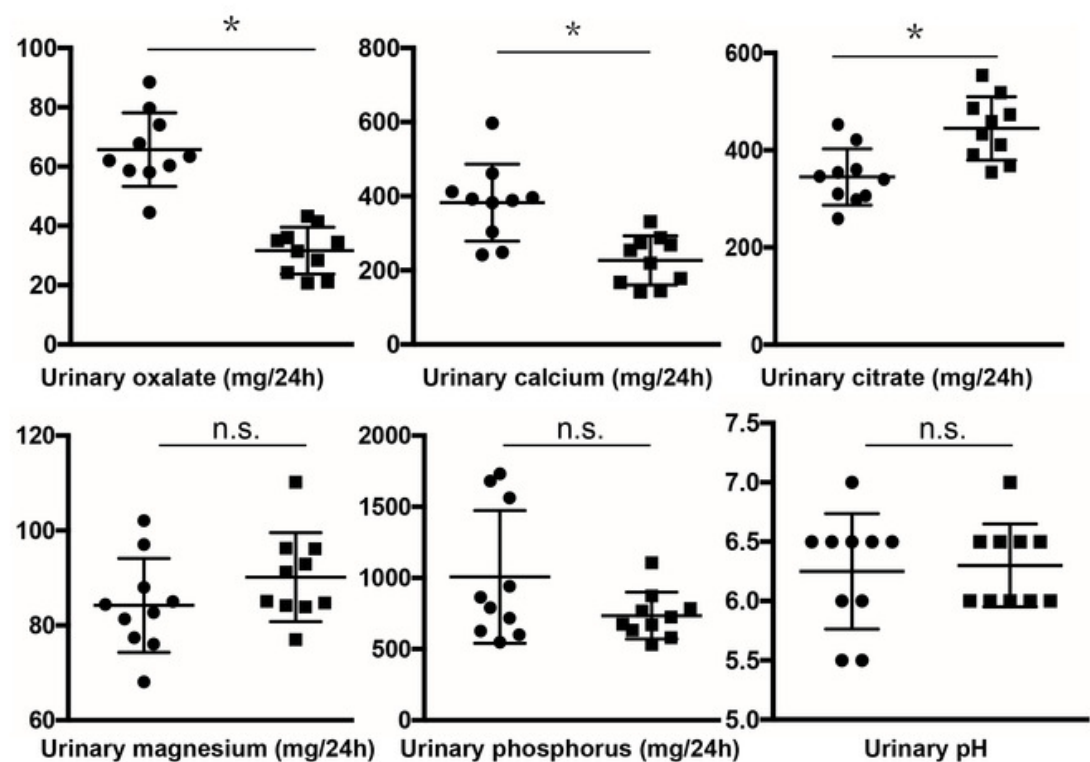

stone formers

$$
\text { nonstone formers }
$$

D

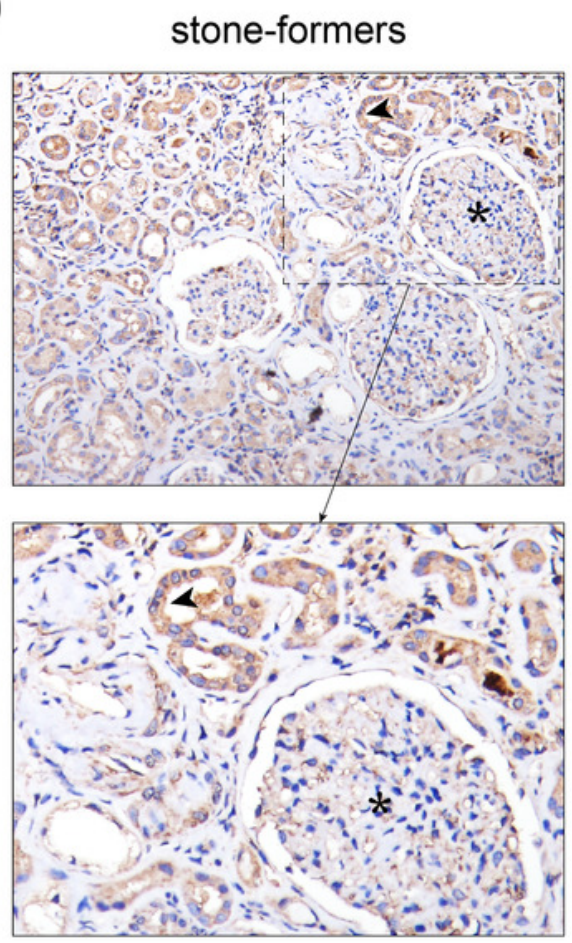

nonstone-formers
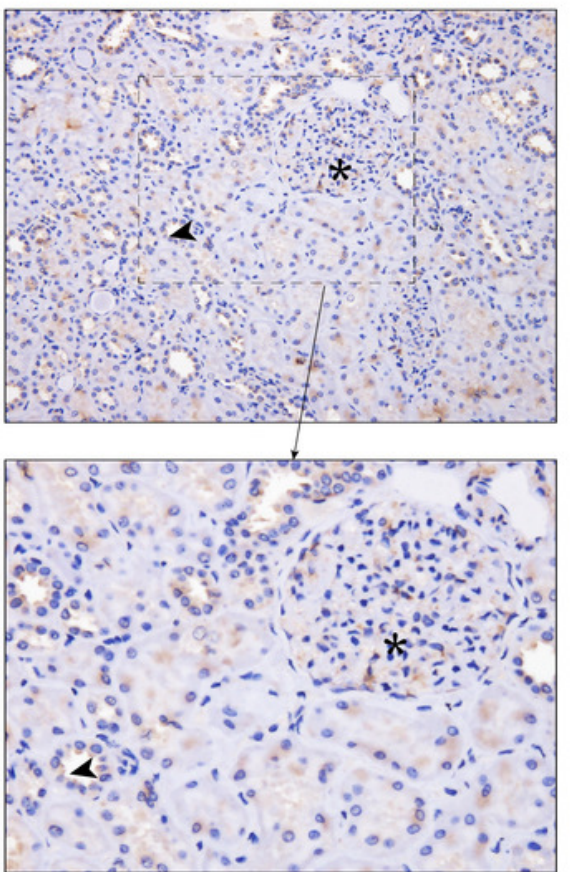

B

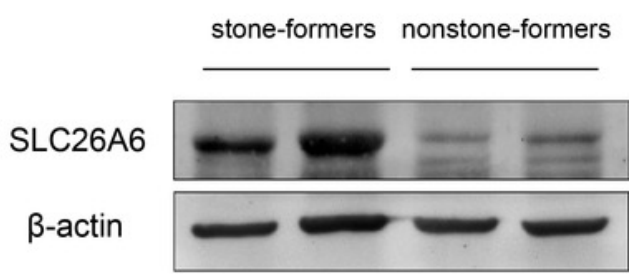

C

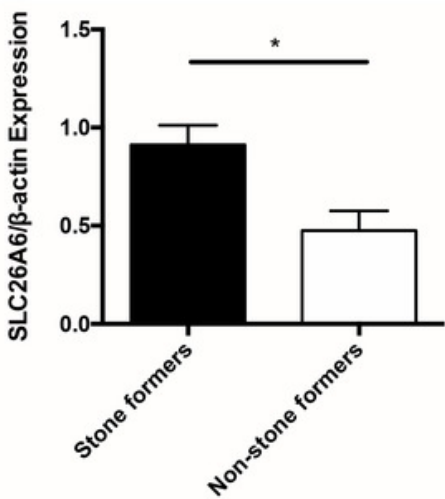

E

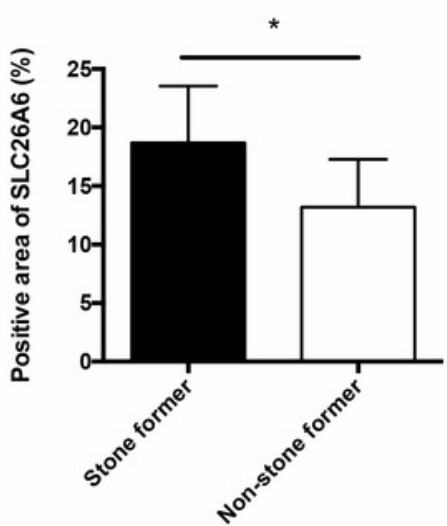




\section{Figure 2}

Lentivirus preparation and transfection detection.

(A) The SIc26a6 sequence was inserted into a lentiviral vector as pWSLV-05-SIc26a6. And dssiRNA anti-SIc26a6 sequence was inserted into a lentiviral vector as pLenti-siRNA(SIc26a6)RFP. (B) After successful lentivirus insertion into the kidneys of rats, frozen sections of kidneys and duodenums were observed under a fluorescence microscope. Cell nucleus were stained with DAPI. RFP was used as a marker to show successful insertion. Compared with the control group, transfection in the kidneys of the experimental groups (IV-SIc26a6 and siRNA-SIc26a6 groups) was successful as seen under a fluorescence microscope (magnification '200). No difference of RFP expression was observed in the duodenum tissue between the control group and the experimental groups. The data are expressed as means \pm $\mathrm{SD}(\mathrm{n}=4 \mathrm{rats} /$ group); $* \mathrm{P}<0.05$. 
A

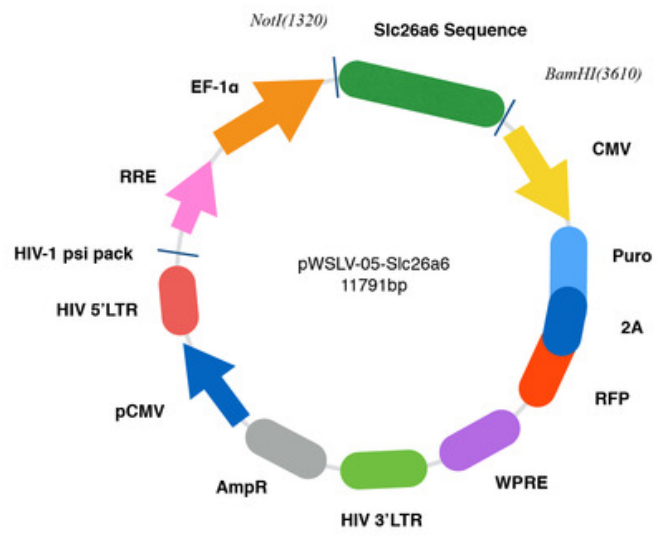

B
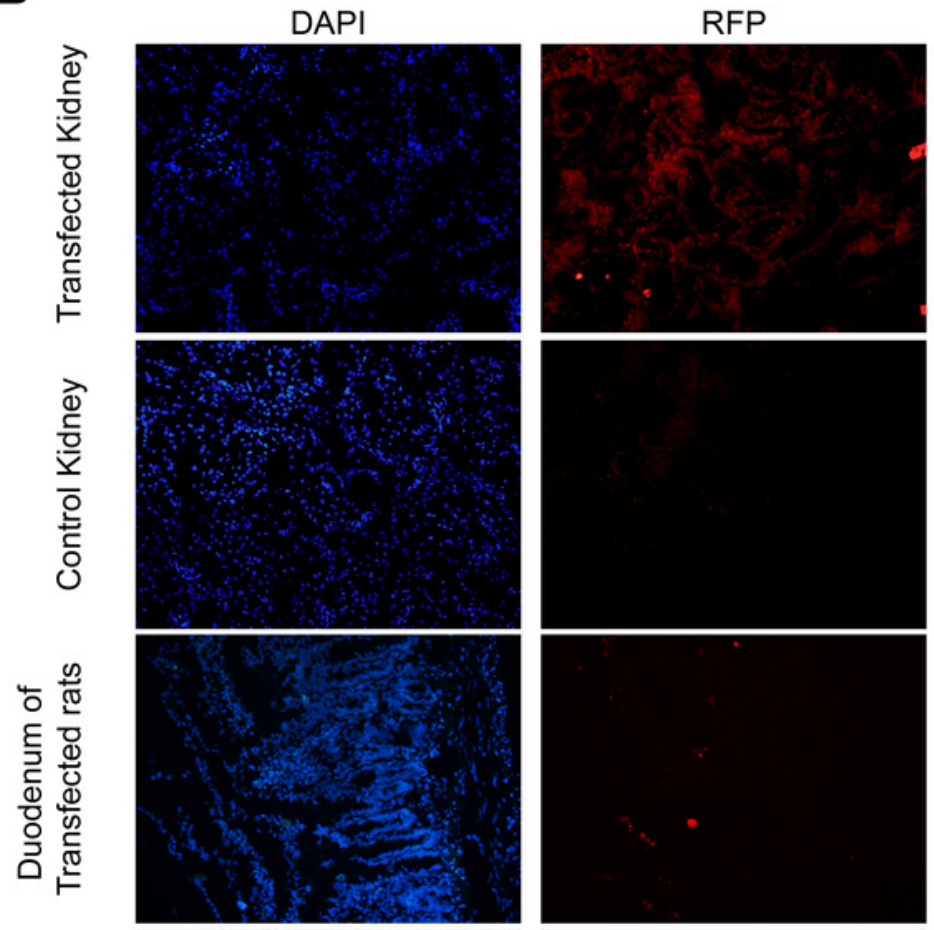

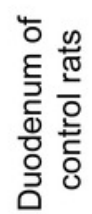
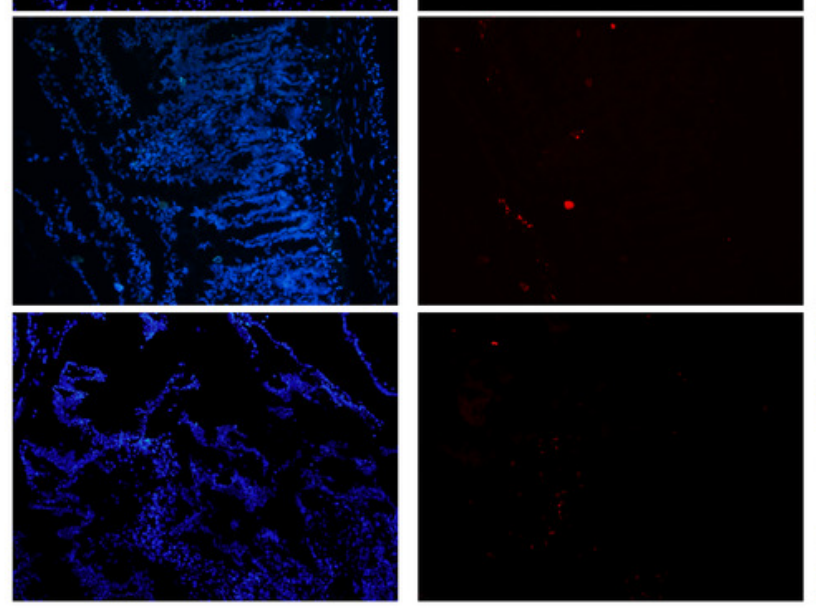
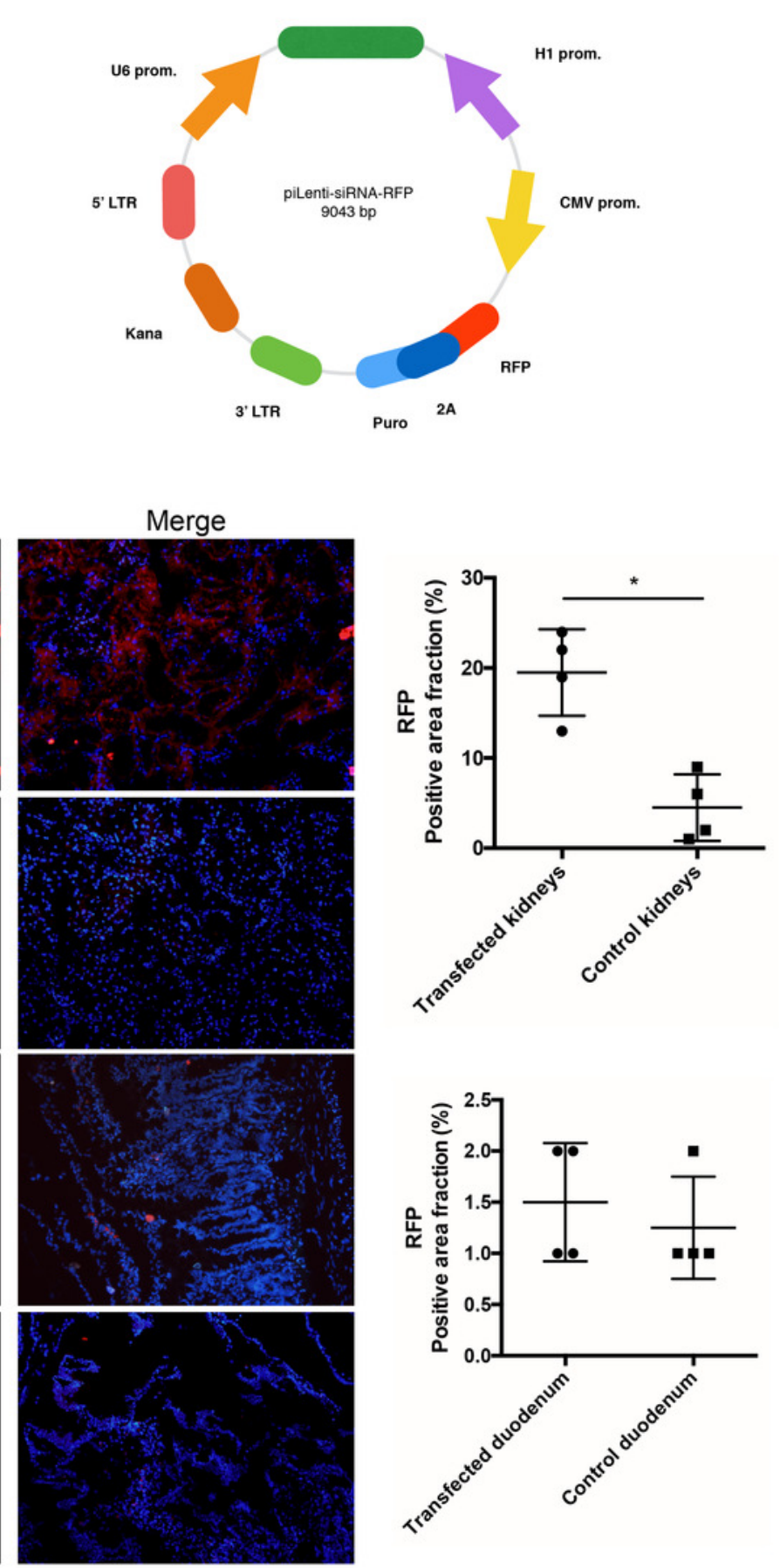


\section{Figure 3}

Expression of SIc26a6 in the duodenal and renal tissues of rats among different groups.

(A) Western analysis of duodenal tissue showed no difference in the expression of SLC26A6 among Iv-SIc26a6, siRNA-SIc26a6, control, and vector groups. The data are expressed as means $\pm S D$ ( $n=4$ rats/group). (B) Evaluation of the expression of renal SIc26a6. The IvSIc26a6 group showed significantly higher expression compared with the control group, while the level reduced in the siRNA-SIc26a6 group. No significant difference was observed in the expression in the vector and control groups. The data are expressed as means $\pm S D(n=4$ rats/group); $* \mathrm{P}<0.05$. (C) Immunohistochemical (IHC) analysis was performed to detect the expression of duodenal SLC26A6 in different groups. No difference was observed in the expression of IV-SIc26a6 (I), siRNA-SIc26a6 (II), control (III), and vector groups (IV). The data are expressed as means $\pm S D$ ( $n=4$ rats/group). (D) IHC was performed to detect the expression of renal SIc26a6 in different groups ( upper magnification: $\times 100$, lower magnification: $\times 400$ ). Lv-SIc26a6 (I) had significantly higher expression compared with the control group (III), whereas siRNA-SIc26a6 (II) had lower expression compared with the control group. No significant difference was observed between the vector (IV) and control groups (III). The data are expressed as means \pm SD ( $n=4$ rats/group); *P $<0.05$. 
A

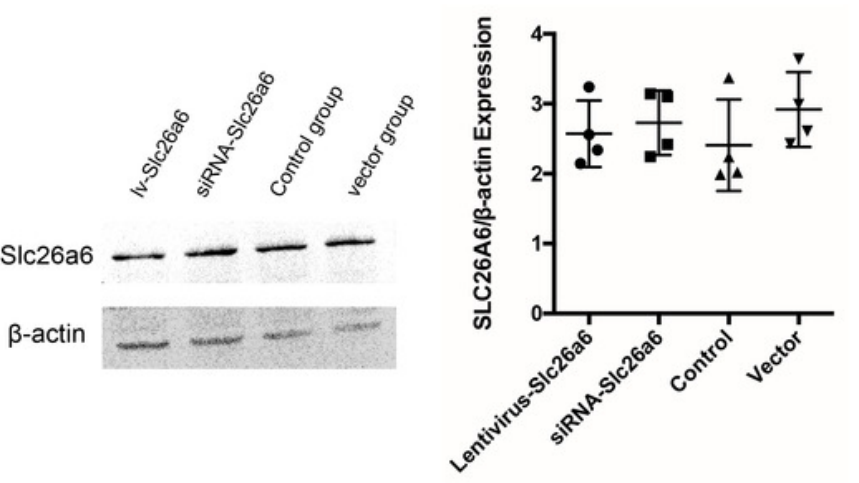

B

C
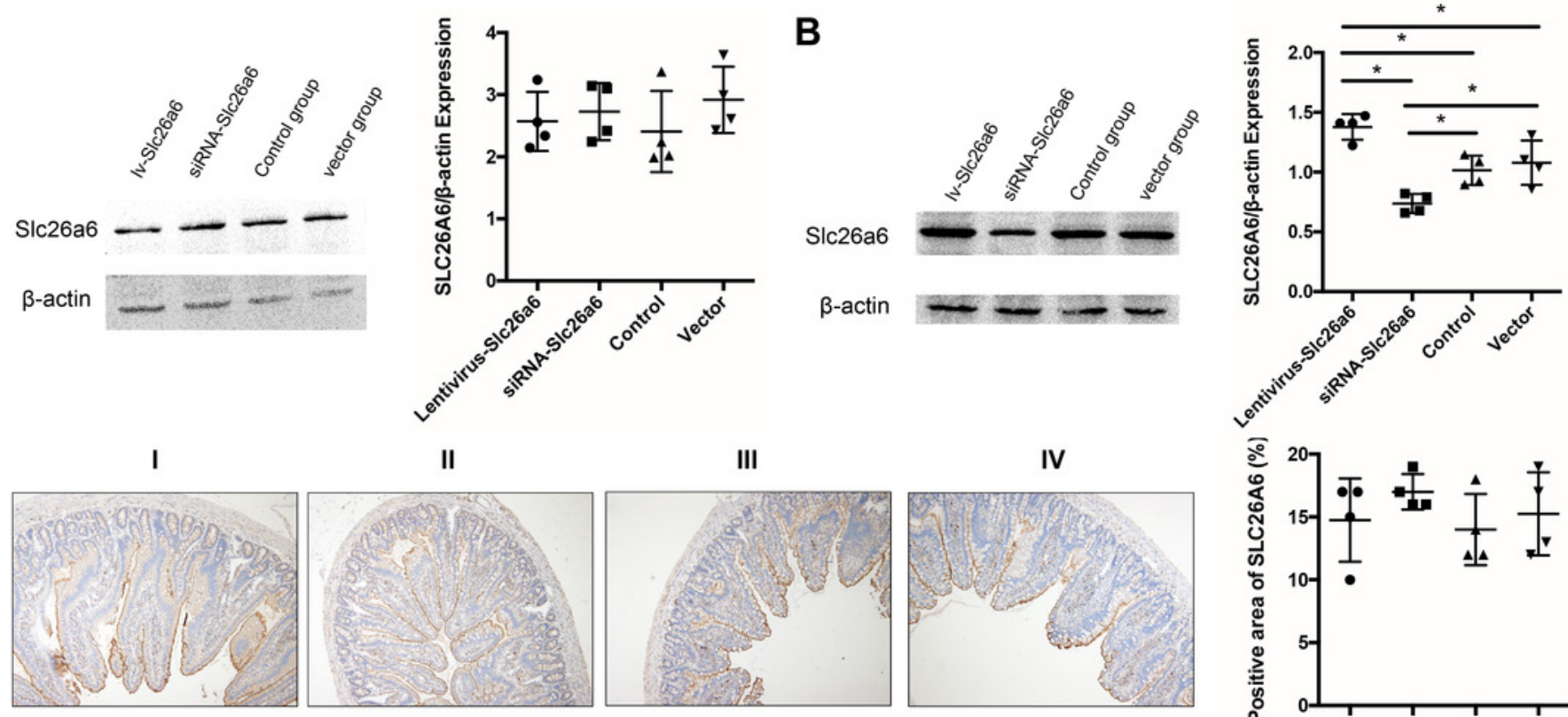

D
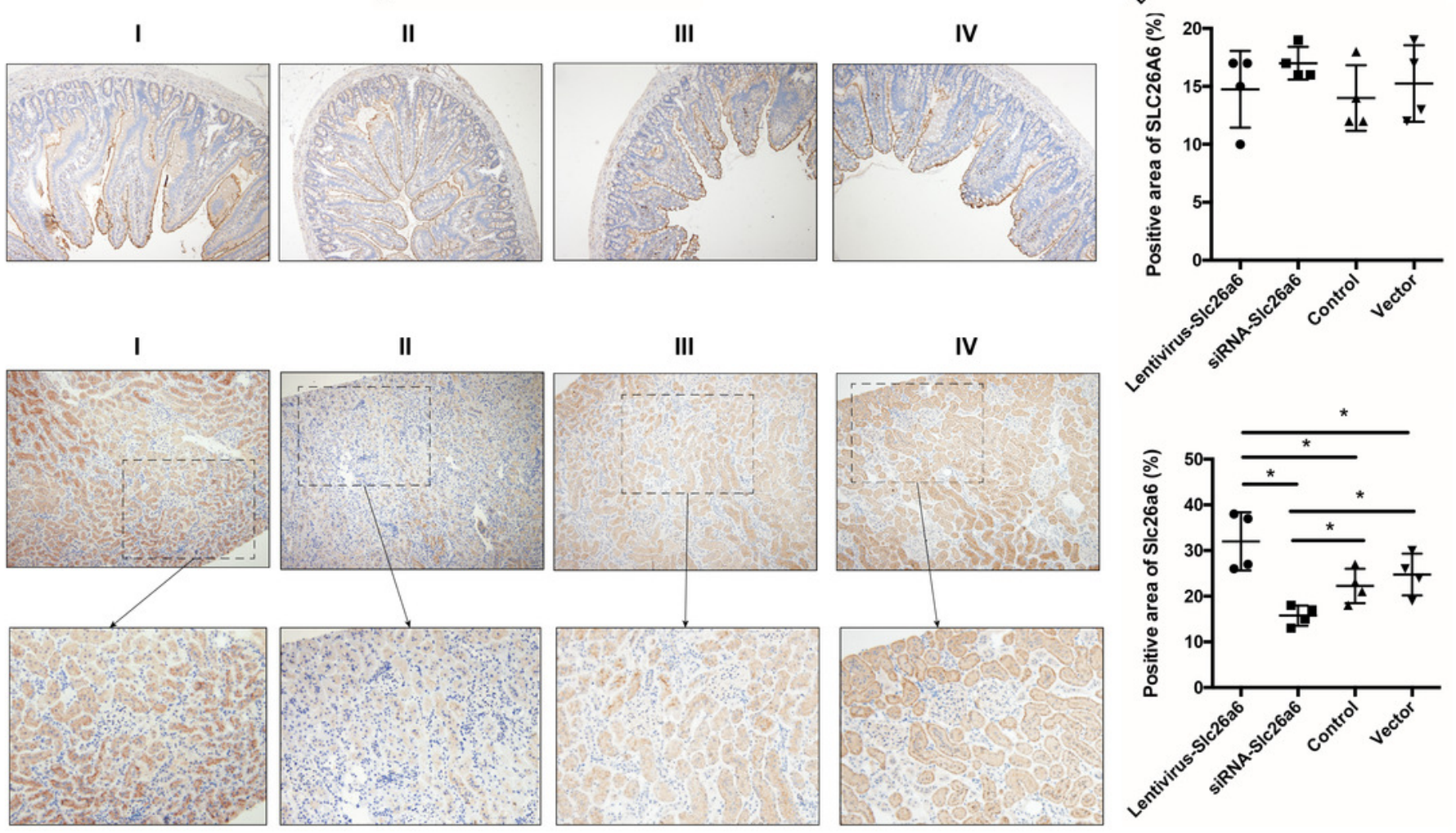


\section{Figure 4}

Transfection with SIc26a6 or siRNA-SIc26a6 led to different urinary oxalate and crystal formation in rats.

(A) Supplementation of the drinking water with 1.0\% EG induced hyperoxaluria; 24-h urine was collected by putting the rats in a metabolic cage. The oxalate level in urine was measured by ion chromatography, and the result showed that SIc26a6-lentivirus-transfected rats had significantly higher urinary oxalate excretion compared with the vector and control groups. siRNA-SIc26a6-transfected rats had less urinary oxalate compared with the control group. The data are expressed as means $\pm S D(n=6$ rats/group); $* P<0.05$. (B) Von Kossa staining was used to observe the crystal formation in different groups. The Slc26a6-lentivirus group had increased crystal formation (B-I) compared with the normal control (B-III) and vector-lentivirus (B-IV) groups. The siRNA-lentivirus (B-II) group had the least crystal formation. Arrows point to crystals (magnification, $\times 200$ ). (C) Crystal formation status in different groups. The SIc26a6-lentivirus group has the highest crystal formation compared with other groups, and the siRNA-SIc26a6 transgenic group had the least crystal formation. The data are expressed as means $\pm \mathrm{SD}(n=6$ rats/group); $* P<0.05$. 


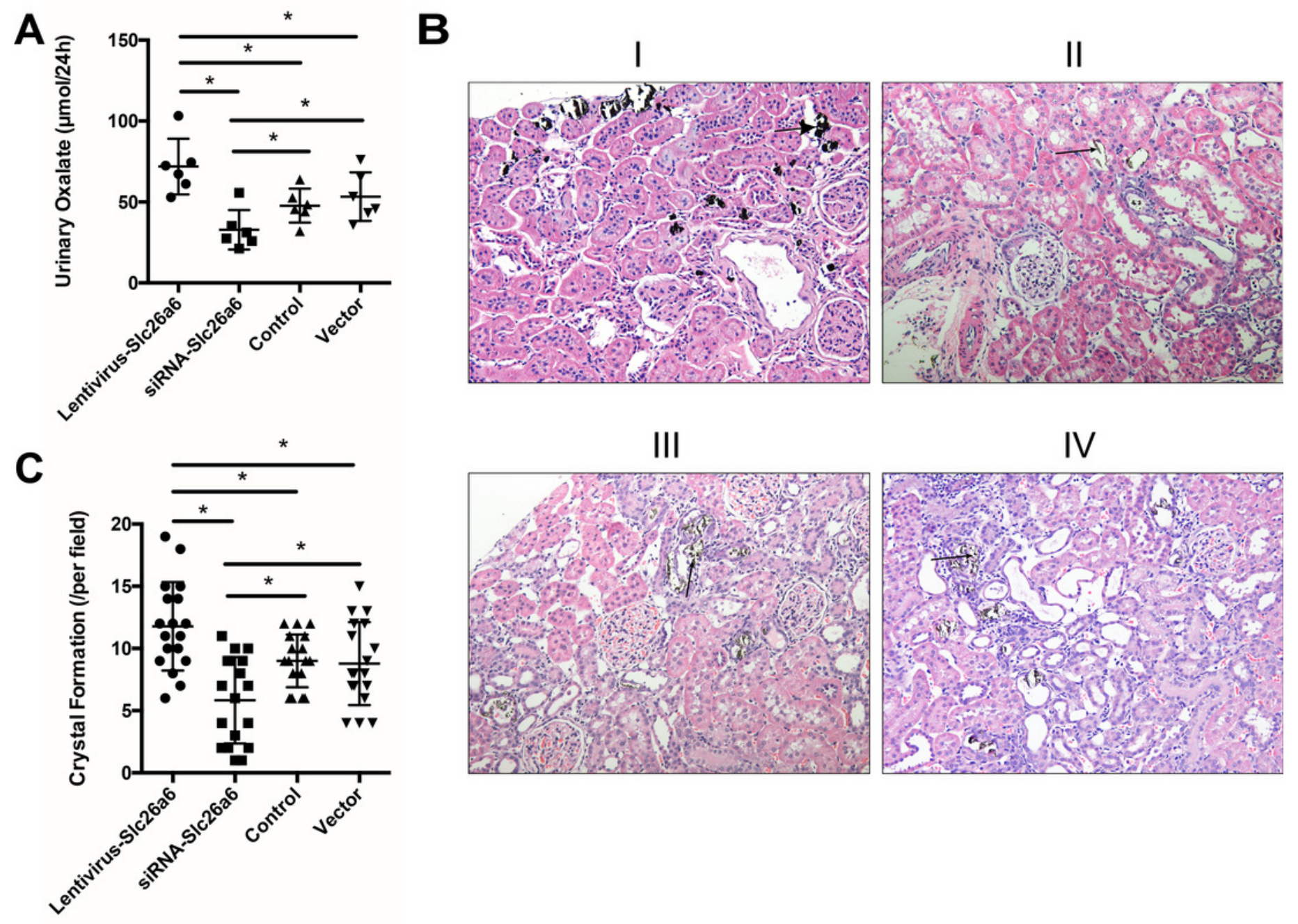




\section{Figure 5}

Proposed mechanisms of oxalate transport across the renal epithelium in the proximal tubule.

In the renal proximal tubule cells, oxalate transport is associated with Slc26a1 expressed on basolateral membrane and SIc26a6 expressed on apical membrane. SIc26al mediates the uptake of oxalate in exchange for reabsorbed sulfate (or $\mathrm{Cl}^{-}$or $\mathrm{HCO}_{3}^{-}$). The high expression of Slc26a6 mediates more secretion by oxalate- $\mathrm{Cl}^{-}$exchange and reabsorption by sulfate-oxalate exchange. According to the results, oxalate- $\mathrm{Cl}^{-}$exchange possessed a dominant position resulting in the enhanced net secretion of oxalate. 


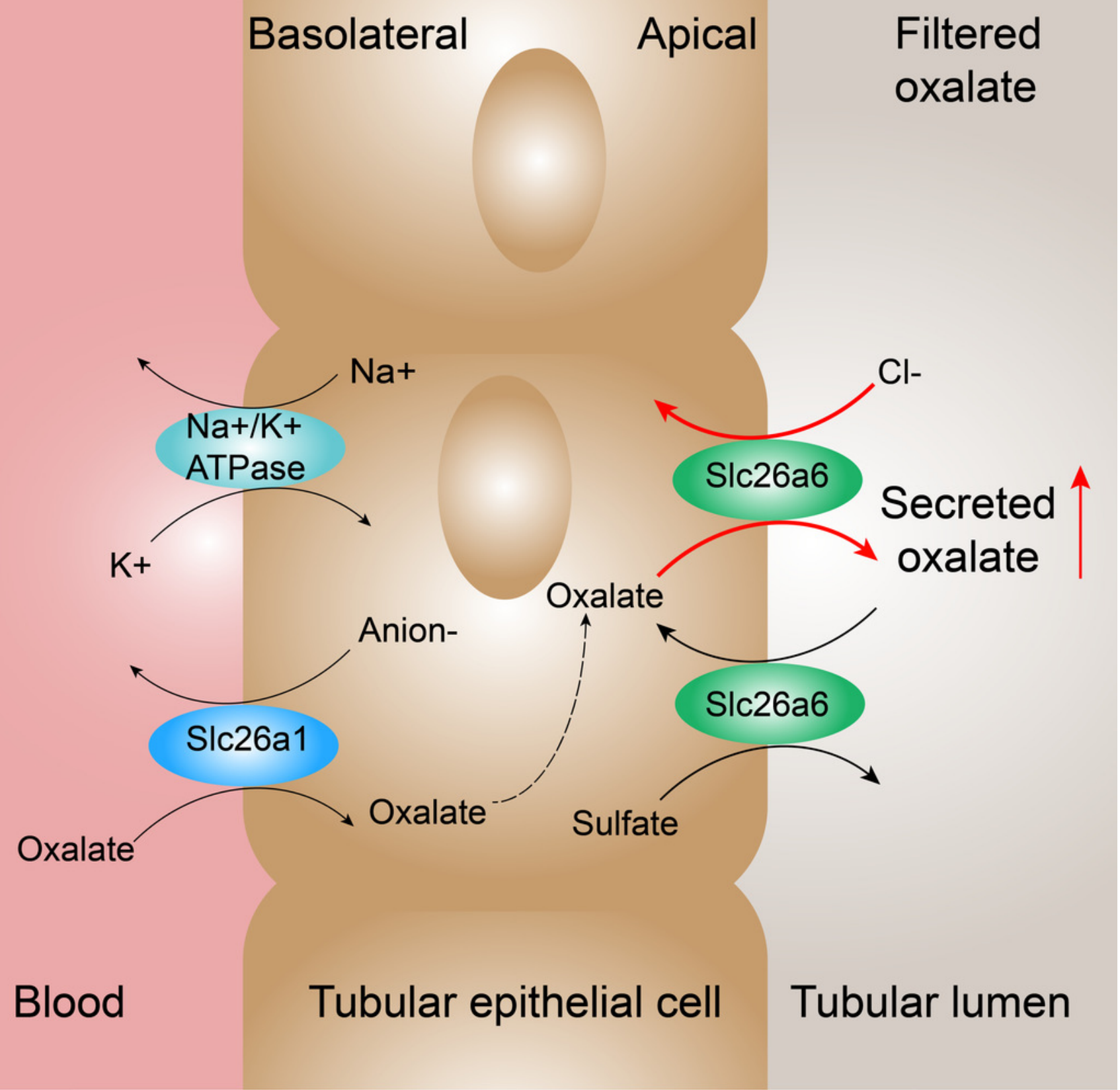




\section{Table 1 (on next page)}

Basic characteristics of patients. 


\begin{tabular}{|c|c|c|c|c|}
\hline Subject & Age (year)/Gender & Dx & Procedure & Stone analysis \\
\hline S1 & $58 / \mathrm{M}$ & Kidney stone (R) & Nephrectomy & $\begin{array}{l}\mathrm{CaC}_{2} \mathrm{O}_{4} \text {, carbonate } \\
\text { apatite }\end{array}$ \\
\hline S2 & $65 / \mathrm{M}$ & Kidney stone (R) & Nephrectomy & $\begin{array}{l}\mathrm{CaC}_{2} \mathrm{O}_{4} \text {, carbonate } \\
\text { apatite }\end{array}$ \\
\hline S3 & $60 / \mathrm{F}$ & $\begin{array}{l}\text { Upper ureteral stone } \\
\text { (L) }\end{array}$ & Nephrectomy & $\begin{array}{l}\mathrm{CaC}_{2} \mathrm{O}_{4} \text {, carbonate } \\
\text { apatite }\end{array}$ \\
\hline S4 & $59 / \mathrm{F}$ & Kidney stone (R) & Nephrectomy & $\begin{array}{l}\mathrm{CaC}_{2} \mathrm{O}_{4} \text {, carbonate } \\
\text { apatite }\end{array}$ \\
\hline S5 & $54 / \mathrm{M}$ & Kidney stone (R) & Nephrectomy & $\begin{array}{l}\mathrm{CaC}_{2} \mathrm{O}_{4} \text {, carbonate } \\
\text { apatite }\end{array}$ \\
\hline S6 & $54 / \mathrm{M}$ & Kidney stone (L) & Nephrectomy & $\begin{array}{l}\mathrm{CaC}_{2} \mathrm{O}_{4} \text {, carbonate } \\
\text { apatite }\end{array}$ \\
\hline S7 & $48 / \mathrm{F}$ & Kidney stone (R) & Nephrectomy & $\begin{array}{l}\mathrm{CaC}_{2} \mathrm{O}_{4} \text {, carbonate } \\
\text { apatite }\end{array}$ \\
\hline S8 & $61 / \mathrm{F}$ & Kidney stone (L) & Nephrectomy & $\mathrm{CaC}_{2} \mathrm{O}_{4}$, carbonate \\
\hline S9 & $56 / \mathrm{M}$ & Kidney stone (R) & Nephrectomy & $\mathrm{CaC}_{2} \mathrm{O}_{4}$, carbonate \\
\hline S10 & $49 / \mathrm{M}$ & Kidney stone (R) & Nephrectomy & $\mathrm{CaC}_{2} \mathrm{O}_{4}$, carbonate \\
\hline $\mathrm{C} 1$ & $27 / F$ & Renal tuberculosis & Nephrectomy & NA \\
\hline $\mathrm{C} 2$ & $69 / \mathrm{F}$ & Kidney tumor $(\mathrm{R})$ & Nephrectomy & NA \\
\hline $\mathrm{C} 3$ & $43 / \mathrm{M}$ & Kidney tumor (R) & Nephrectomy & NA \\
\hline
\end{tabular}




\begin{tabular}{|c|c|c|c|c|}
\hline $\mathrm{C} 4$ & $49 / F$ & Renal tuberculosis & Nephrectomy & NA \\
\hline $\mathrm{C} 5$ & $76 / \mathrm{F}$ & Kidney tumor $(\mathrm{R})$ & Nephrectomy & NA \\
\hline C6 & $58 / \mathrm{F}$ & Renal tuberculosis & Nephrectomy & NA \\
\hline $\mathrm{C} 7$ & $54 / \mathrm{M}$ & Kidney tumor $(\mathrm{R})$ & Nephrectomy & NA \\
\hline $\mathrm{C} 8$ & $68 / \mathrm{F}$ & Kidney tumor $(\mathrm{R})$ & Nephrectomy & NA \\
\hline C9 & $61 / \mathrm{M}$ & Kidney tumor $(\mathrm{R})$ & Nephrectomy & NA \\
\hline $\mathrm{C} 10$ & $43 / \mathrm{M}$ & Kidney tumor (L) & Nephrectomy & NA \\
\hline
\end{tabular}

2 S: stone former group; C: control group; F: female; M: male; Dx: diagnosis; R: right; L: left; NA: none

3 